\title{
ANALYSIS OF A LARGE INDUSTRIAL ENTERPRISE POWER SUPPLY PROBLEMS FROM THE POSITION OF GENERAL SYSTEM PRINCIPLES ON THE EXAMPLE OF LLC HARVESTER PLANT "ROSTSELMASH"
}

\author{
Natalia Fedorova ${ }^{1, *}$, and Vera Bundikova ${ }^{1}$ \\ ${ }^{1}$ Platov South-Russian State Polytechnic University (NPI), 346428, Rostov region, Novocherkassk, Prosveshcheniya, 132, Russia
}

\begin{abstract}
An industrial enterprise is a complex technical system that interacts with the external environment. The structure and activities of an enterprise are subject not only to technical, economic, legal laws, but also to the laws of general systems theory. This article explores possible ways to improve the efficiency of a large industrial enterprise from the standpoint of system-wide principles.
\end{abstract}

\section{Introduction}

Industrial enterprises, regardless of the scale and profile of their activities, consume energy resources for industrial and domestic purposes: electricity, thermal energy (in the form of hot water, steam, hot air, etc.), direct combustion fuel (including motor fuel), mechanical energy (to create excess pressure and discharge, displacement), energy from unconventional sources (solar, wind), water, air, natural or other gas as energy and technological resources, working fluids in various processes. Energy costs can account for a significant proportion of production costs.

Federal Law No. 261 «On Energy Saving» [1] obliges enterprises to take measures to reduce the level of energy consumption. By introducing energy saving measures:

- the enterprise receives an economic effect in the form of a reduction in the cost of purchased energy resources;

- the consumption of energy resources per unit of production and the cost of production are reduced, which increases the competitiveness of products in the market; - due to the modernization of equipment, the reliability of operation is increased, the likelihood of accidents decreases;

- improving the environmental situation at the enterprise and near it.

But in the conditions of a group of related enterprises, an increase in efficiency, including energy, of one of them can lead to a decrease in the efficiency of the other. Striving to achieve maximum efficiency indicators for the entire group of enterprises in aggregate can lead to the fact that each of the enterprises of the group will work with not the best technical and economic indicators. There is a horizontal conflict of interest. In order for enterprises to be interested in achieving precisely the aggregate maximum efficiency, they must know their profit from this - in the form of direct financial bonuses, legal guarantees of stable work, and risk reduction.

\section{General characteristics of LLC «Harvester plant Rostselmash»}

Under favorable socio-economic and legal conditions, under the implementation of a sound development strategy, high demand for the company's products, the development of sales markets, the development of new technologies, types of products and related industries, the takeover of related small industries, the parent company develops and expands. At a certain point, a qualitative leap occurs and individual divisions of a large enterprise can function as independent narrow-profile enterprises, and a large enterprise as a whole is transformed into a holding.

This is the story of Rostselmash. It began operations in 1929 as a grain harvester and forage harvester factory. Now it is a holding, a group of companies consisting of 13 enterprises with assembly plants located in Russia, USA, Canada, Ukraine and Kazakhstan, which occupies a strong position in the five largest world manufacturers of agricultural machinery. It employs about 11,000 people, producing 24 types of agricultural machinery. Rostselmash is a Russian non-resource sector company that has become transnational.

The part of the holding located in the Rostov Region is called the Public Joint Stock Company (PJSC) «Rostselmash». In fig. 1 shows the organizational scheme of Rostselmash PJSC, in fig. 2 - Rostselmash PJSC power supply scheme.

* fedorovanv61@rambler.ru 


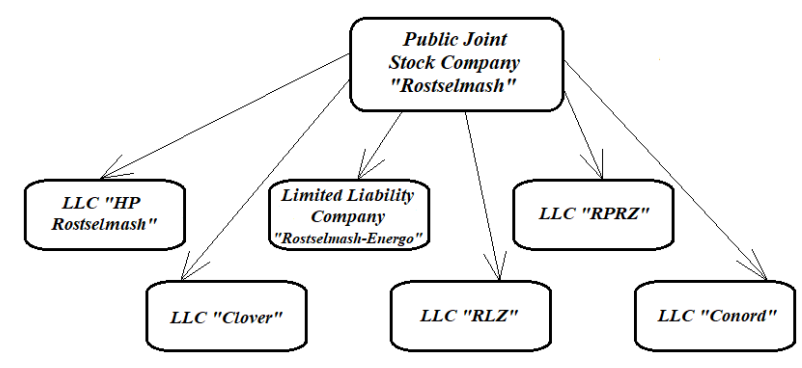

Fig. 1 Organizational scheme of Rostselmash PJSC.

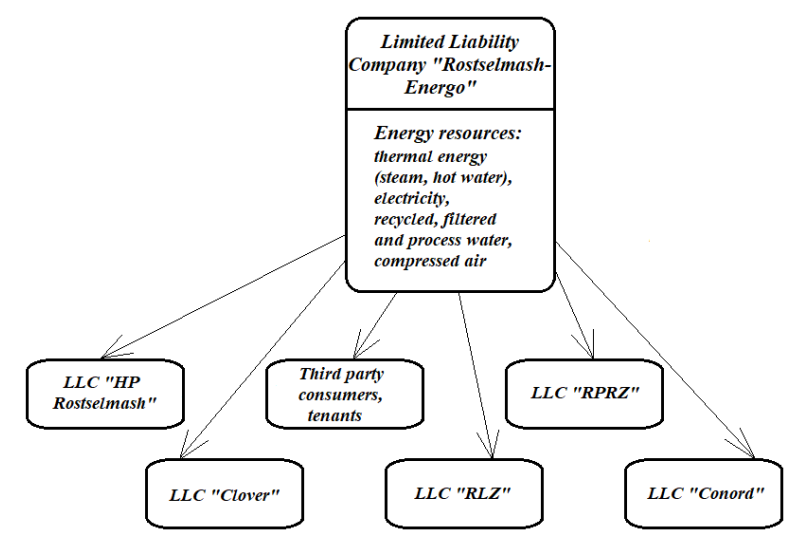

Fig. 2 Rostselmash PJSC power supply scheme.

One of the subdivisions of Rostselmash PJSC - the Rostselmash Harvester Plant Limited Liability Company (HP Rostselmash LLC), is located on the historical territory of Rostselmash in Rostov-on-Don, other subdivisions are either there or in other areas Rostov region. All divisions are supplied with energy by Rostselmash-Energo LLC. However, each enterprise pursues its own energy policy, concluding agreements with Rostselmash-Energo LLC for energy supply and paying for these services, solving independently the issues of repair and modernization of electricity and heating networks. Employees of HP Rostselmash LLC plan the energy policy of their subdivision and bear responsibility for it. But the power equipment is serviced by employees of Rostselmash-Energo LLC, who are not legally, organizationally and financially subordinate to the management of KZ Rostselmash LLC and fulfill the tasks of their management. LLC "Rostselmash-Energo", pursuing its own interests, can, as a matter of priority, serve third-party consumers.

\section{The holding systems functioning}

Holding [2] is an organization that owns controlling stakes in other companies in order to exercise control and management functions in relation to them. There are different types of holding structures: integrated industrial companies, conglomerates, banking and media holdings. Characteristic features of holdings [3]: concentration of shares of companies in any industry located in different regions / countries, and multistage, the presence of subsidiaries at several levels. At the same time, the peculiarity of the industrial holding is the transformation of material flows and the formation of a material commodity product.

The functioning of holding systems has a number of advantages: the possibility of creating closed technological chains from the extraction of raw materials to the release of finished products and bringing them to the consumer; savings on trade, marketing and other services; taking advantage of production diversification; uniform tax and credit and financial policy; the ability to vary financial and investment resources within the holding system. Each enterprise, having entered in the holding system, becomes economically interested in the effective activities of all subjects of the holding, but at the same time retains a certain economic independence. Strategic issues are under the jurisdiction of the parent company, operational and tactical issues are under the jurisdiction of subsidiaries.

Disadvantages of holdings: lack of competition within the holding, which leads to the preservation of unprofitable industries and a decrease in the economic efficiency of the entire holding; bureaucratization of the management apparatus, complication of management processes and workflow, the complexity of a large association managing; the lack of a developed legal and regulatory system for the regulation of holdings. In the Rostselmash holding is observed another drawback excessive autonomy of subsidiaries.

An industrial holding, as an object of system analysis, is a complex, open, dynamic, technical, organized and purposeful [4] system. The main goal of its functioning in the conditions of the capitalist market is to obtain the maximum possible profit. At the same time, each division of the holding is also a system object that functions in interaction with the external environment and has the goal of earning its own profit. The influence of the holding management on a separate unit is, on the one hand, a control action, to which it is necessary to react in the manner expected by the management. But on the other hand, this is the impact of some element of the external environment, which, of course, must be taken into account, but not forget about its own benefits. This is how a vertical conflict of interest arises. And the more independent a unit is, the more sharply it can be expressed. But in case of excessive centralization of the holding, in the absence of sufficient powers and resources, sufficient independence for the subdivision, it may not cope with the functions assigned to it.

\section{Activity of HP Rostselmash LLC from the position of general system principles}

Each enterprise is a system object that interacts with the external environment. The larger the enterprise, the more complex its structure and the more clearly system-wide principles are manifested in its activities [5]. Let's consider the functioning and problems of HP Rostselmash LLC from the standpoint of system-wide principles [6]. 
The main system-forming principle is the principle of monocentrism [7]. A stable system «is characterized by one center, and if it is complex, chain, then it has one higher, common center». Polycentric systems are characterized by dysfunction of coordination processes, disorganization, instability. The structure of Rostselmash is non-transparent, the management hierarchy is not well-built, and individual production units, even being at the same site, are autonomous in their actions and building the internal structure. The issues of energy supply are solved independently by individual production units (subdivisions), as well as the issues of production financing.

Energy supply of production facilities and energy saving issues cannot be considered separately from technological processes. Production efficiency must be assessed not only from the standpoint of achieving quantitative and qualitative indicators of products, but also from the point of view of energy efficiency in conducting technological processes, moreover, within the holding as a whole. At factories built more than 15 years ago, most processes can be performed $15-20 \%$ more efficiently without compromising product quality. Lighting and heating systems can be significantly improved. Downtime and overtime occur due to the inconsistency of the work of the departments and the transport and logistics service. Depending on the nature of production and the technical perfection of an industrial enterprise, the introduction of innovative energy-saving measures can give from 5 to $30 \%$ energy savings.

Without significant capital investment and the purchase of new technologies, industrial enterprises can be optimized through an unconventional approach to energy conservation. But for this, at least, all enterprises of the holding must obey a single management. Implementation of a unified energy-saving policy (for example, switching to energy-saving light sources or pipes made of modern heat-insulating materials) at Rostselmash is problematic with its modern structure.

According to the principle of organizational continuity [7], any system is fundamentally open in relation to its internal composition, open to element-byelement and complex modification. The autonomy of individual production facilities of Rostselmash, perhaps, helps them to solve certain specific tasks, but it closes these production facilities for external management, closes their internal composition and structure. And thus it casts doubt on the thesis of a single complex system HP Rostselmash LLC.

Feedback principle [8]. Stability in complex dynamic systems is achieved by closing the feedback loops. At Rostselmash, in conditions of excessive autonomy and insufficient centralization, there is no feedback from subsidiaries - to the parent company of the holding. Individual subsidiaries (divisions) are not interested in changing the hierarchy of the holding, as this will reduce the degree of control for them over their own resources, finances, and potential profit. But from the point of view of increasing the efficiency of energy supply, both parties are interested in establishing feedback between the power engineers of the subsidiary and parent companies.

The principle of integrity (emergence), says that the system has properties that the elements that make up its composition do not have. The properties of the system are not equal to the sum of the properties of its elements. «In some cases, the product of the compound is not a simple sum of individual elements, but is a new creation» [9]. An industrial holding unites into one system enterprises involved in various (ideally at all) stages of a certain product making, located in different cities and countries. This makes it possible to use material, energy, labor resources, features of legislation and tax policy of these territories, and to produce innovative version of the product using fundamentally new efficient technologies. It is this task that should be set by the management of the parent company. The demand for Rostselmash's products, access to international markets indicate that this task has been set and, in general, is being solved. But the energy supply to the units is not efficient. Modern technologies of electricity and heat supply, local energy resources are not used sufficiently. Subsidiaries are in no hurry to invest their finances and other resources in the renewal of the energy supply system, and the parent company does not pursue a strict energy saving policy. It should be admitted that the principle of integrity is not observed with regard to the energy supply of Rostselmash.

The principle of the limiting factor [10] says: the overall stability of the system is determined by its least partial stability. Given the autonomy of individual Rostselmash production facilities, each production has its own «weak link». And the limiting factor in the development of a group of companies of 13 enterprises located in 5 countries is not geographic disunity, which should result in increased attention to the transport and logistics service, the need, first of all, to fine-tune its structure, adequate to production, its material and staffing, its clear and well-coordinated work. The limiting factor and the main systemic problem of Rostselmash as a unified system is the excessive autonomy of individual companies and the obvious absence of a single rigid governing center.

\section{Conclusions}

Consideration of the activities of HP Rostselmash LLCas an element of the holding and a subsystem of a single complex system made it possible to identify key problems that hinder to implement a unified energy saving policy and thereby to reduce the cost and to increase the competitiveness of products. Violation of the principle of monocentrism entails a chain of violations of other system-wide principles and leads to the missed financial gain of the owner. And the main systemic problem of Rostselmash is the presence of a limiting factor - the excessive autonomy of certain divisions of the holding. Strengthening the role of the center in the management of the holding, at least for the divisions united geographically, for pursuing a unified policy, including in the development and financing of 
projects aimed at solving the problems of energy supply and energy saving, will increase the economic efficiency of the holding as a whole. As a result, this should bring benefits to each separate division of the holding. Increasing the efficiency of the unit's energy supply cannot be considered in isolation from the energy supply of the holding as a whole. The autonomy of the subdivisions should remain within the solution of specific technological issues.

\section{References}

1. Federal Law «On Energy Saving and on Increasing Energy Efficiency and on Amending Certain Legislative Acts of the Russian Federation» dated 23.11.2009 № 261-FL

2. Milner, B.Z. Organization theory / B.Z. Milner // M.: Infra-M, 2000. -480 p.

3. BusinessMan.ru: https://businessman.ru/newxolding-eto-struktura-deyatelnost-xoldingovupravlenie-xoldingom.html

4. Mesarovich, M. General theory of systems: mathematical foundations / M. Mesarovich, Ya. Takahara // M.: Mir, 1978. - 311 p.

5. Freidina, E.V. Research of control systems: Educational-methodical complex / E.V. Freidin // Novosibirsk: NSUEM, 2007. - 184 p.

6. Fedorova, N.V. Power supply of an industrial holding as an object of system analysis / N.V. Fedorova, V.R. Bundikova // Innovative clustering of science and practice in the context of digitalization: collection of articles on the results of International scientific-practical conf. - SPb.: Publishing house of SPbGEU, 2020. - P. 20-23. https://www.elibrary.ru/item.asp?id=42445421

7. Bogdanov, A.A. Tectology: General Organizational Science. In 2 books. / A.A. Bogdanov / M.: Economics, 1989. - 304 pp., 351 p.

8. Ashby, U.R. Introduction to cybernetics / U.R. Ashby // Moscow: Foreign Literature, 1959. - 432 p.

9. Elfimov, G.M. The concept of «new» in the theory of emergent evolution / G.M. Elfimov // Management consulting. - 2009, № 1. - P. 187-122.

10. Takhtadzhyan, A.L. Tectology: history and problems / A.L. Takhtadzhyan // System Studies. Yearbook. - Moscow: «Science», 1971. - P. 245. 